Human Ethology Bulletin 30 (2015)4: 8-22

Research Article

\title{
THE ROLE OF INTELLIGENCE IN MATING: AN INVESTIGATION OF HOW MATING INTELLIGENCE RELATES TO MATE SELECTION AND MATING-RELEVANT CONSTRUCTS
}

\author{
Stefanie Gisler \& T. Joel Wade \\ Department of Psychology, Bucknell University, Lewisburg, PA, USA \\ stefanie.gisler@gmail.com
}

\begin{abstract}
Mating intelligence is a fairly new construct with only limited empirical examination. Yet, previous research has found important implications for the construct's role in mating behavior. The present study sought to expand the existing body of research on mating intelligence by investigating its relationship with self-esteem, self-perceived attractiveness, and mate selection. A sample of 195 participants (83 males and 112 females) completed a survey that incorporated measures of mating intelligence, self-esteem, and self-perceived attractiveness. Additionally, participants were asked to choose between an attractive and unattractive mate to take out on a date. Significant positive relationships between mating intelligence, self-esteem, and self-perceived attractiveness were found for both sexes. For males, mating intelligence predicted self-esteem over and above selfperceived attractiveness. Both males and females with higher mating intelligence were more likely to select the attractive mate to date. Self-perceived attractiveness predicted self-esteem for both sexes, but the relationship was stronger for males.
\end{abstract}

Key words: Mating intelligence, self-esteem, self-perceived attractiveness, mate selection, partner choice. 


\section{INTRODUCTION}

One of the core domains of evolutionary psychology is to understand adaptive behaviors as a function of reproduction. The discipline's focus tends to be on human universals such as sex-specific differences. However, evolutionary psychology often neglects individual differences, which are a crucial factor in human mating (Geher \& Kaufman, 2011; Geher \& Miller, 2008). A fairly new construct, mating intelligence intends to broaden the realm of evolutionary psychology through incorporating intelligence (Geher \& Kaufman, 2011). Mating intelligence has been defined as the most important form of intelligence from an evolutionary perspective. It links some aspects of human intelligence, such as creativity and humor, to mating behavior (Geher \& Miller, 2008).

The Mating Intelligence Scale was developed by Geher and Kaufman (2007) to measure mating intelligence. In order to define the realm of mating intelligence more precisely, they established the following domains: cross-sex mind reading (awareness of mate's interest), mating-relevant self-deception (confidence in personal mate value), mating-relevant otherdeception (ability to manipulate mates), and cognitive courtship display (using creativity and other aspects of intelligence relevant to mating). In addition, two sex-specific domains have been defined: males benefit from sexual over-estimation, and females benefit from commitment skepticism (Haselton \& Buss, 2000; O’Brien, Geher, Gallup, Garcia, \& Kaufman, 2010). Only a handful of studies have employed the scale to investigate mating related topics.

O'Brien et al.'s (2010) study on hook-ups in college students was one of the first empirical investigations of mating intelligence. They found that for men, mating intelligence positively correlated with number of sex partners. Men with high mating intelligence scores were more likely to engage in Type I (with strangers) and Type III (with friends), but not in Type II (with acquaintances) hook-ups. In addition to that, men who never engaged in a hook-up had significantly lower mating intelligence scores. For women, mating intelligence was linked to an earlier loss of virginity, but having engaged in a hook-up did not correlate with mating intelligence. However, there were some differences in types of hook-up. Those with high mating intelligence were more likely to have had Type II (with acquaintances), but not Type I (with strangers) or Type III (with friends) hook-ups.

Additional studies have linked mating intelligence to preferences for sex acts and ovulatory shifts. Peterson, Geher, and Kaufman (2011) investigated how mating intelligence and dispositional variables relate to sex acts. They found that mating intelligence predicts a preference for a variety of sex acts. In fact, mating intelligence emerged as the strongest predictor among the dispositional variables that were investigated in the study. For both sexes, mating intelligence was positively related to preference for vaginal intercourse, but some sex differences emerged.

Another study examined the relationship between mating intelligence and ovulation. The results indicated that mating intelligence scores in women increase when conception probability increases. This was only the case for women with natural cycles. No significant effects for women using hormonal forms of birth control were found (Peterson, Carmen, \& 
Geher, 2013). Most recently, a study has found that mating intelligence is a predictor of individuals' mate value as well as the mate value of their partners. In other words, individuals tend to select mates closer to their own mate value (Dillon, Adair, Geher, Wang, \& Strout, 2015).

\section{Self-esteem}

There is a dearth of empirical research on mating intelligence, despite its promising associations with variables relevant to mating. Geher and Kaufman (2013) indicated that self-esteem is likely to be related to mating intelligence, but the relationship between the two constructs has not been investigated as of yet. From an evolutionary perspective, self-esteem is a set of internal representations of individual characteristics that influence reproductive fitness (Barkow, 1989). Some of the attributes that affect self-esteem include physical prowess, health, status, resources, attractiveness, and intrasexual rank (Hill \& Buss, 2006).

Most of all, self-esteem is determined through interaction with and feedback from others (Patrick, Neighbors, \& Knee, 2004). One way interactions with others affect individuals' self-esteem is through social comparison. Generally, people are more likely to compare themselves to individuals who are similar to them (Festinger, 1954). Thornton and Moore (1993) found that there is a drop in self-esteem whenever people compare themselves to individuals with desirable characteristics, while comparison to less attractive others leads to a rise in self-esteem.

An important aspect of self-esteem is individuals' mate value, both self-perceived and as perceived by others (Hill \& Durante, 2013). Mate value indicates how attractive someone is as a potential mate (Brase \& Guy, 2004). In order to increase mate value, self-enhancements such as working out and acquiring new clothes can be used (Brase \& Guy, 2004; Hill \& Durante, 2013; Park \& Manner, 2009). Individuals in romantic relationships are less likely to use self-enhancements, and they tend to have higher self-esteem than those without significant others (Brase \& Guy, 2004; Hill \& Durante, 2013). Furthermore, married individuals have higher self-esteem compared to divorcees (Hill \& Durante, 2013).

Mate value and self-esteem do not always coincide. For example, self-esteem has been negatively correlated with the ages when individuals have the highest mate value. This holds particularly true for women. Self-esteem starts out high in childhood, but declines during adolescence once individuals become sexually mature. Its lifetime low is between ages 18 and 22 and it does not increase again until individuals reach their fifties. Independent of age, women's self-esteem decreases once they reach peak fertility during their ovulation cycle (Hill \& Durante, 2013).

Some studies have found that men tend to have higher self-esteem than women (Brase \& Guy, 2004). Gender specific attributes matter as well. For men, attributes associated with strength and dominance are related to self-esteem, while for women, body related fecundity is the strongest predictor (Wade, 2000). These attributes not only affect individuals' selfesteem, but they also influence how attractive they are to the opposite sex. 


\section{Self-perceived attractiveness}

Attractiveness has been a major area of research in evolutionary psychology because mate value is largely determined by it. However, the emphasized traits differ between the sexes. For women, cues of fertility as indicated by physical attractiveness are more salient, while for men, greater emphasis is placed on the ability to provide resources (Greitmeyer, 2005). Nevertheless, both men and women respond to indicators of physical attractiveness because they signal reproductive fitness (Backman \& Adams, 1991).

For both sexes, facial averageness and symmetry are related to physical attractiveness, but more emphasis is placed on the body for women (Neave \& Shields, 2008). One of the most prominent physical indicators is women's waist-to-hip ratio. Women with a smaller waist-tohip ratio are considered more feminine, more attractive, and healthier (Wade, 2000). For men, physical attractiveness is based on markers for dominance, status, masculinity, and health (Wade, 2000).

Attractiveness factors also strongly influence how we perceive ourselves. Individuals judge their bodies in terms of how they match valuable reproductive characteristics, which serves as a function to assess intrasexual and intersexual competitiveness. Furthermore, individuals gauge their attractiveness through getting feedback from others (Wade \& Cooper, 1999). This affects the way they perceive their own attractiveness. However, the accuracy of self-perception differs between the sexes. Women tend to be quite accurate in assessing their actual attractiveness, as evaluated by others. Men, on the other hand, are less accurate in evaluating their own attractiveness (Rand \& Hall, 1983).

For both men and women, actual attractiveness is only moderately related to self-esteem, but there is a strong correlation between self-perceived attractiveness and self-esteem (Hatfield \& Sprecher, 1986). Self-perceived physical attractiveness has stronger implications for women's self-esteem than for men's because of the stronger emphasis on physical cues for women. Men's mate value, which is based primarily on status and the ability to provide resources, cannot be as easily assessed. Bale and Archer (2013) found that in both men and women self-perceived attractiveness significantly predicted self-esteem. Other research found that the link between self-perceived attractiveness and self-esteem was significant for women, but not for men (Wade, 2000). Besides the difference between the sexes, the relationship between self-perceived attractiveness and self-esteem depends on age. The link between the two constructs is especially strong in late adolescence (Thornton \& Moore, 1993).

\section{Mate selection}

In addition to its effects on self-esteem, self-perceived attractiveness also influences mate selection. Both sexes select mates based on their own mate value, but they find different characteristics more desirable (Tadinac \& Hromatko, 2007). Women with high selfperceived physical attractiveness place greater importance on mate characteristics that indicate the ability to provide resources. For men, self-perceived physical attractiveness is not as important for their mate value, and it does not influence mate preferences. Their mate 
selection criteria are related to their ability to provide resources. Those that have an aboveaverage income place the highest importance on good looks. In other words, there is an exchange between the sexes: women offer looks in exchange for resources. Physical attractiveness is very important for men, while social and financial status is more important for women (Buss, 2003; Tadinac \& Hromatko, 2007). The underlying goal of this exchange is reproductive success (Todd, Penke, Fasolo, \& Lenton, 2007).

However, the degree to which individuals seek characteristics related to attractiveness is context dependent. It matters whether they are seeking a short- or a long-term relationship (Todd et al., 2007). Women tend to prefer long-term relationships due to the higher level of resources and protection they offer (Garcia \& Reiber, 2008). There are high costs involved for women if they engage in indiscriminate mating (e.g. unwanted pregnancy) (Jonason, Norman, \& Cason, 2009). Men, on the other hand, tend to prefer short-term relationships to enhance their reproductive potential. In order to attain a short-term mate, they often select women with lower mate value because women with higher mate value tend to be more selective. When women engage in short-term relationships, they usually go for a more attractive mate who is more likely to pass down good genes to a potential offspring (Buss \& Schmitt, 1993; Garcia \& Reiber, 2008).

\section{Present research}

The present study expands on the previous findings on mating intelligence by investigating its relationship with self-esteem, self-perceived attractiveness, and mate selection. Based on prior research, we tested the following hypotheses:

1. Mating intelligence is positively related to self-esteem for both sexes.

2. Mating intelligence is positively related to self-perceived attractiveness for both sexes.

3. Self-perceived attractiveness is positively related to self-esteem. The relationship is expected to be stronger for women than for men.

Mating intelligence is positively related to mate selection. Individuals who score higher on mating intelligence are more likely to select a physically attractive mate.

\section{METHODS}

\section{Participants}

Data were collected from a total of 195 participants, of which 112 were women and 83 were men. The ages ranged from 18 to $56(M=22.62, S D=9.82)$. The sample had the following demographic characteristics: 86\% Caucasian, 4\% African American, 2\% Hispanic, 6\% Asian/Asian-American, $1 \%$ Native American, and 2\% Other. Of the participants, $82 \%$ have been in a sexual relationship and $18 \%$ have never been in a sexual relationship. Furthermore, $55 \%$ were currently single, $39 \%$ were in a relationship, and $6 \%$ were unsure. For women, 
$61 \%$ were currently using some form of hormonal birth control and 39\% were not using hormonal birth control. Only heterosexual participants were included in the sample.

\section{Procedure}

This study was approved by the Institutional Review Board (IRB) at a private University in the Northeastern U.S. An online survey was created and distributed to 800 randomly selected students (400 females and 400 males). Additionally, the link was posted on the campus' online message board, Facebook, and Craigslist. All responses were recorded anonymously.

\section{Measures}

The online survey entailed the following items: informed consent, demographic questions, Mating Intelligence Scale, Current Thoughts Scale, Self-Perceived Attractiveness and Related Criteria, mate selection, and a debriefing statement.

Demographic questions. Participants were given the following demographic questions: gender, age, race/ethnicity, sexual orientation, whether they have been in a sexual relationship, current relationship status, and whether they are currently on birth control medication. They were also asked to list any doctor prescribed medication they were presently taking.

Mating Intelligence Scale. (Geher \& Kaufman, 2007). Based on their sex, participants were given either the female or the male version of the Mating Intelligence Scale. Each version has 24 true/false statements. Depending on the item, participants received either one or zero points. The scoring differs for each version. The reliability of the scale was lower for females than for males, but it was still within an acceptable range (Females: Cronbach's $a=.65$; Males: Cronbach's $\alpha=.84$ ).

Current Thoughts Scale (Heatherton \& Polivy, 1991). The Current Thoughts Scale was used to assess participants' self-esteem. It is a modified version of the Janis-Field Feelings of Inadequacy Scale (Janis \& Field, 1959). It contains 20 items that are divided into the following subscales: Performance, Social, and Appearance. One item (no. 18) that asked about scholastic ability was modified so that it was also applicable to non-students. Each item was scored on a 5-point scale: $1=$ not at all, $2=$ a little bit, $3=$ somewhat, $4=$ very much, and $5=$ extremely. Thirteen items were reverse scored. This scale was employed because it measures various domains of self-esteem, some of which are relevant to mating.

Self-perceived Attractiveness and Attraction Related Criteria (Wade, 2000). Self-perceived attractiveness was measured by asking participants to rate their attractiveness (face and body) as well as attraction related criteria, such as strength and dominance, on a scale from 1 to 7 . The scale consists of 9 items.

Mate selection. Participants were given two pictures of the opposite sex (one attractive and one unattractive) and they were asked to indicate whom they would ask out on a date. The 
pictures were downloaded from a free stock image website. A short questionnaire was used to evaluate which pictures should be included in the survey. For each sex 6 pictures were selected, of which 3 portrayed potentially attractive and 3 portrayed potentially unattractive individuals. A total of 11 participants were asked to rate each picture on a Likert scale on the following items: friendliness, nurturance, and attractiveness. The mean attractiveness of each photo was assessed and the pictures that had the highest mean values were used for the attractive category, while those with the lowest mean values were used for the unattractive category.

\section{RESULTS}

Due to the different versions of the mating intelligence scale, all analyses were conducted separately for each sex. The mean mating intelligence score for men was $11.90(S D=5.17$, Range $=2-22$ ). Women scored slightly higher on average, with a mean mating intelligence score of $12.24(S D=3.63$, Range $=2-19)$. Both men and women had very similar mean selfesteem scores (Males: $M=72.07, S D=13.93$, Range $=42-96$; Females: $M=72.22, S D=$ 13.52 , Range $=27-100)$. On the self-perceived attractiveness measure, women $(M=46.39$, $S D=6.70$, Range $=24-63)$ had a higher mean score compared to men $(M=44.82, S D=7.51$, Range $=27-59)$.

\section{Correlations among variables}

Correlation analyses were conducted to evaluate the relationships between the variables (see Tables 1 and 2). Supporting hypotheses 1, 2, and 4, mating intelligence was positively correlated with self-esteem (Males: $r=.46, p<.01$; Females: $r=.25, p<.01$ ), self-perceived attractiveness (Males: $r=.61, p<.01$; Females: $r=.38, p<.01$ ), and mate selection (Males: $r=$ $.49, p<.01$; Females: $r=.32, p<.01)$. Partially supporting hypothesis 3 , self-esteem was positively correlated with self-perceived attractiveness for both sexes (Males: $r=.48, p<.01$; Females: $r=.40, p<.01$ ), but there was no significant relationship between self-esteem and mate selection. Contrary to the third hypothesis, the relationship between self-esteem and self-perceived attractiveness was stronger for men than for women. Self-perceived attractiveness was positively correlated with mate selection for men $(r=.33, p<.01)$, but not for women.

Table 1. Correlations among variables for males $(N=83)$

\begin{tabular}{lccc}
\hline \multicolumn{1}{l}{ Mating intelligence } & $\mathbf{1}$ & $\mathbf{2}$ & $\mathbf{3}$ \\
\hline 2. Self esteem & & & \\
$\begin{array}{l}\text { 3. Self-perceived } \\
\text { attractiveness }\end{array}$ & $.46^{* *}$ & & \\
4. Mate selection & $.61^{* *}$ & $.48^{* *}$ & $.33^{* *}$ \\
\hline
\end{tabular}

Note. ${ }^{*} \mathrm{p}<0.05^{* *} p<.01$. 
Table 2. Correlations among variables for females $(N=112)$

\begin{tabular}{lccc}
\hline & $\mathbf{1}$ & $\mathbf{2}$ & $\mathbf{3}$ \\
\hline $\begin{array}{l}\text { 1. Mating intelligence } \\
\text { 2. Self esteem }\end{array}$ & $.25^{* *}$ & & \\
$\begin{array}{l}\text { 3. Self-perceived } \\
\text { attractiveness }\end{array}$ & $.38^{* *}$ & $.40^{* *}$ & \\
4. Mate selection & $.32^{* *}$ & -.02 & .11 \\
\hline
\end{tabular}

Note. ${ }^{*} \mathrm{p}<0.05^{* *} p<.01$.

\section{Hierarchical regressions predicting self-esteem}

Hierarchical regression analyses were conducted to evaluate if mating intelligence predicts self-esteem over and above self-perceived attractiveness (see Tables 3 and 4). For men, selfperceived attractiveness explained $22.7 \%$ of the variance in self-esteem $\left(R^{2}=.23, F(1,82)=\right.$ $23.822, p<.01)$. The addition of mating intelligence significantly improved prediction $\left(R^{2}\right.$ change $=.05, F=5.198, p<.05)$. Together the variables explained $27.4 \%$ of the variance $\left(R^{2}=\right.$ $.274, F(2,82)=15.127, p<.01)$. Both self-perceived attractiveness $(\beta=.309, p<.05)$ and mating intelligence $(\beta=.274, p<.05)$ significantly predicted self-esteem.

For women, self-perceived attractiveness explained $15.8 \%$ of the variance in self-esteem $\left(R^{2}=\right.$ $.16, F(1,111)=20.665, p<.01)$. The addition of mating intelligence did not significantly improve prediction. Thus, only self-perceived attractiveness significantly predicted selfesteem $(\beta=.355, p<.01)$.

Table 3. Hierarchical regression analysis for variables predicting self-esteem in males $(N=83)$

\begin{tabular}{|c|c|c|c|c|c|c|}
\hline & \multicolumn{3}{|c|}{ Model 1} & \multicolumn{3}{|c|}{ Model 2} \\
\hline & B & SE B & $\boldsymbol{\beta}$ & B & SE B & $\boldsymbol{\beta}$ \\
\hline $\begin{array}{l}\text { Self-perceived } \\
\text { attractiveness }\end{array}$ & .885 & .181 & $.477^{* *}$ & .574 & .223 & $.309^{*}$ \\
\hline $\begin{array}{l}\text { Mating } \\
\text { intelligence }\end{array}$ & & & & .738 & .324 & $.274^{*}$ \\
\hline $\boldsymbol{R}^{2}$ & & $.23^{* *}$ & & & $.27^{*}$ & \\
\hline $\mathbf{F}$ & & 23.822 & & & 15.127 & \\
\hline
\end{tabular}

Note. ${ }^{*} \mathrm{p}<0.05^{* *} p<.01$. 
Table 4. Hierarchical regression analysis for variables predicting self-esteem in females $(N=112)$

\begin{tabular}{|c|c|c|c|c|c|c|}
\hline & \multicolumn{3}{|c|}{ Model 1} & \multicolumn{3}{|c|}{ Model 2} \\
\hline & B & SE B & $\boldsymbol{\beta}$ & B & SE B & $\beta$ \\
\hline $\begin{array}{l}\text { Self-perceived } \\
\text { attractiveness }\end{array}$ & .802 & .176 & $.398^{* *}$ & .715 & .190 & $.355^{* *}$ \\
\hline $\begin{array}{l}\text { Mating } \\
\text { intelligence }\end{array}$ & & & & .422 & .352 & .133 \\
\hline$R^{2}$ & & $.16^{* *}$ & & & .17 & \\
\hline $\mathbf{F}$ & & 20.665 & & & 11.092 & \\
\hline
\end{tabular}

Note. ${ }^{*} \mathrm{p}<0.05^{* *} p<.01$.

\section{Logistic regressions predicting mate selection}

Due to the binary nature of the mate selection variable (attractive/unattractive), logistic regression analyses were conducted to evaluate if mating intelligence, self-esteem, and selfperceived attractiveness predict mate selection (see Tables 5 and 6). Men with higher mating intelligence were more likely to select the attractive mate $(\mathrm{B}=.510, \mathrm{SE}=.146$, Wald $=$ $12.107, \mathrm{p}<.01)$. An individual was predicted to be $51 \%$ more likely to select the attractive mate with a 1-point increase on the scale. Self-esteem was also a significant predictor for mate selection $(\mathrm{B}=-.075, \mathrm{SE}=.032$, Wald $=5.629, \mathrm{p}<.05)$, but the relationship was negative. With a 1-point increase on the self-esteem scale, men were predicted to be $7.5 \%$ less likely to select the attractive mate. Self-perceived attractiveness was not a significant predictor. Women with higher mating intelligence were also more likely to select the attractive mate (B $=.248, \mathrm{SE}=.083$, Wald $=8.867, \mathrm{p}<.01)$. An individual was predicted to be $24.8 \%$ more likely to select the attractive mate with a 1-point increase on the scale. Neither self-esteem nor selfperceived attractiveness were significant predictors.

Table 5. Logistic regression analysis for variables predicting mate selection in males $(N=83)$

\begin{tabular}{lccccc}
\hline & $\boldsymbol{B}$ & $\boldsymbol{S E}$ & Wald & $\boldsymbol{p}$ & $\begin{array}{c}\text { Odds } \\
\text { Ratio }\end{array}$ \\
\hline Mating intelligence & .510 & .146 & 12.107 & .001 & 1.665 \\
Self-esteem &. .075 & .032 & 5.629 & .018 & .928 \\
Self-perceived attractiveness & .036 & .058 & .374 & .541 & 1.036 \\
\hline
\end{tabular}


Table 6. Logistic regression analysis for variables predicting mate selection in females $(N=112)$

\begin{tabular}{lccccc}
\hline & $\boldsymbol{B}$ & $\boldsymbol{S E}$ & Wald & $\boldsymbol{p}$ & $\begin{array}{l}\text { Odds } \\
\text { Ratio }\end{array}$ \\
\hline Mating intelligence & .248 & .083 & 8.867 & .003 & 1.282 \\
Self-esteem & -.028 & .024 & 1.346 & .246 & .972 \\
Self-perceived attractiveness & .015 & .045 & .112 & .738 & 1.015 \\
\hline
\end{tabular}

\section{DISCUSSION}

The results were partially consistent with the hypotheses. Mating intelligence, self-esteem, and self-perceived attractiveness were all positively related to each other. However, contrary to hypothesis 3, the relationship between self-perceived attractiveness and self-esteem was stronger for men than for women. Both men and women who scored higher on mating intelligence were more likely to select the attractive mate.

\section{Mating intelligence and self-perceived attractiveness}

For both sexes, mating intelligence and self-perceived attractiveness were positively correlated with each other. For women, the finding that self-perceived attractiveness and mating intelligence are correlated supports previous research on self-perceived attractiveness. Women's mate value is highly dependent on physical attractiveness, and attractive females are likely to experience more interest from the opposite sex due to males' preference for physically attractive women (Buss, 2003; Tadinac \& Hromatko, 2007). According to Rand and Hall (1983), women tend to be quite accurate in assessing their actual attractiveness. Thus, individuals with higher self-perceived attractiveness tend to be evaluated as attractive by others, and therefore, their mate value is high. Awareness of one's mate value (mating-relevant self-deception) is one of the domains in mating intelligence, which would explain the positive relationship between self-perceived attractiveness and mating intelligence.

For men, the relationship between mating intelligence and self-perceived attractiveness needs to be evaluated differently than for women. Although there was a positive correlation between self-perceived attractiveness and mating intelligence for men, their self-perceived attractiveness score was likely less strongly based on physical attractiveness because attractiveness in males is more influenced by social and financial status (Greitmeyer, 2005). Men who are able to signal those characteristics during initial contact with a potential mate tend to be more successful. Bale, Morrison, and Caryl (2005) found that chat-up lines that demonstrate generosity and dominance were more likely to appeal to women. Thus, these men's success in talking to women shows that they know what characteristics women are interested in and they are aware that they possess these characteristics. Both are cognitive processes relevant to mating intelligence. 


\section{Mating intelligence and self-esteem}

Mating intelligence was not a significant predictor for self-esteem in women. A possible explanation for this finding is that women's self-esteem is less dependent on some of the mating intelligence domains. Women's mate value is strongly based on attractiveness, and therefore, intellectual properties are less important in initiating first contact with a potential mate. In addition to that, women control access and for that reason, they usually do not have to work as hard in order to attract a mate (Buss \& Schmitt, 1993). Consequently, women can be more direct than men when chatting-up a potential mate. Some of the most effective chat-up lines for women are asking a man on a date or giving him their phone number (Wade, Butrie, \& Hoffman, 2009). Furthermore, the fact that mating intelligence did not predict self-esteem over and above self-perceived attractiveness indicates that self-perceived attractiveness is a more salient predictor for women's self-esteem.

For men, on the other hand, initial contact with a woman strongly affects their reproductive potential. When a man approaches a woman, his success will be largely dependent on his ability to display personal qualities (Bale et al., 2009; Wade, Auer, \& Roth, 2009). In other words, men have to rely more on their intellect to attract a mate. Moreover, characteristics relevant to attractiveness have been linked to men's self-esteem. Those characteristics include the ability to provide resources and status (Greitmeyer, 2005). The ability to display these less visible characteristics towards a potential mate is more challenging than the display of physical attractiveness because it involves high-order cognitive processes. This would explain that mating intelligence is a significant predictor of self-esteem over and above self-perceived attractiveness. Men with higher mating intelligence are more successful in displaying attractive characteristics towards women, and successful mate attraction in turn positively influences their self-esteem.

\section{Self-esteem and self-perceived attractiveness}

The finding that self-perceived attractiveness significantly predicts self-esteem in women is in line with previous research. Contradictory to some of the previous findings (see Wade, 2000), the relationship between self-perceived attractiveness and self-esteem was stronger for men. However, most investigations on self-perceived attractiveness and self-esteem have focused on physical attractiveness. As mentioned earlier, in this study, the scale that was used to assess self-perceived attractiveness also included some items that apply more strongly to characteristics relevant to men's mate value. Furthermore, the relationship between self-perceived attractiveness and self-esteem is especially strong in late adolescence (Thornton \& Moore, 1993). The mean age of the sample was 22.62, and therefore, many of the participants were near or in the age range that has the strongest link between self-esteem and self-perceived attractiveness. This could have affected the results.

\section{Mate selection}

It was hypothesized that individuals who score higher on mating intelligence will be more likely to select the attractive mate. The results supported the hypothesis for both sexes. 
Individuals with higher mating intelligence scores were more likely to select the attractive over the unattractive mate. Dillon et al., (2015) found that mating intelligence is related to both ratings of self and partner's physical attractiveness, establishing mating intelligence as a valid predictor of mate value. However, their research examined mating intelligence in the context of existing relationships. The present study focused on mate selection. In the mate selection process, higher mating intelligence indicates that an individual has the cognitive abilities to attract an attractive mate. For individuals with lower mating intelligence, asking an attractive member of the opposite sex out on a date could be too risky because it could result in a rejection.

Self-perceived attractiveness was not a significant predictor for mate selection in either sex, but self-esteem was significant for men. However, the relationship was negative, indicating that men with higher self-esteem are less likely to select the attractive mate. Similar to the relationship between self-esteem and self-perceived attractiveness, age may have confounded the findings. The age range of the majority of the participants does not adequately reflect self-esteem of the overall population. Self-esteem is at its low-point between ages 18 and 22, which reflect the ages of the majority of our sample (Hill \& Durante, 2013; Robins et al., 2002).

\section{Conclusion}

This research adds to the small yet expanding body of research examining mating intelligence. The findings suggest that mating intelligence predicts self-esteem over and above self-perceived attractiveness for men, and that it plays a role in mate selection for both sexes. Individuals with higher mating intelligence were more likely to select an attractive mate, while self-esteem and self-perceived attractiveness did not have the same effects. Thus, mating intelligence seems to play an important role in the mate selection process.

\section{Limitations and future study}

Although the age of participants ranged from 18 to 56, the mean age was 22.62. This limits the generalizability of the results. Future studies should include a more diverse population. It is also unclear to what degree the Mating Intelligence Scale reflects actual mating intelligence because it assesses self-perceptions. Furthermore, some of the items might be prone to social desirability bias. Thus, a measure of social desirability should be included in future studies. Experimental designs that evaluate mating intelligence in a laboratory or field setting could enhance the validity of the construct. A laboratory setting in which participants fill out the measures and select a mate would allow for greater control of extraneous variables. In addition, the mate selection measure would benefit from greater standardization (i.e. same background color and camera angle) and the use of designated software to manipulate facial attractiveness. 
Gisler, S. \& Wade, T.J.: The Role of Intelligence in Mating

Human Ethology Bulletin 30 (2015)4: 8-22

\section{REFERENCES}

Backman, C. B. (1991). Self-perceived physical attractiveness, self-esteem, race, and gender. Sociological Focus, 24, 283-290. DOI

Bale, C., \& Archer, J. (2013). Self-perceived attractiveness, romantic desirability and self-esteem: A mating sociometer perspective. Evolutionary Psychology, 11, 68-84. DOI

Bale, C., Morrison, R., \& Caryl, P. G. (2005). Chat-up lines as male sexual displays. Personality and Individual Differences, 40, 655-664. DOI

Barkow, J. (1989). Darwin, sex, and status. Toronto: University of Toronto Press. DOI

Brase, G. L., \& Guy, E. C. (2004). The demographics of mate value and self-esteem. Personality and Individual Differences, 36, 471-484. DOI

Buss, D. M. (2003). Evolution of Desire. New York, NY: Basic Books.

Buss, D. M., \& Schmitt, D. P. (1993). Sexual strategies theory: An evolutionary perspective on human mating. Psychological Review, 100, 204-232. DOI

Dillon, H. M., Adair, L. E., Geher, G., Wang, Z., \& Strouts, P. H. (2015). Playing smart: The mating game and mating intelligence. Current Psychology: A Journal for Diverse Perspectives on Diverse Psychological Issues. DOI

Festinger, L. (1954). A theory of social comparison processes. Human Relations, 7, 117-140. DOI

Garcia, J. R., \& Reiber, C. (2008). Hook-up behavior: A biopsychological perspective. Journal of Social, Evolutionary, and Cultural Psychology, 192-208. DOI

Geher, G., \& Kaufman, S. B. (2007). The mating intelligence scale. Psychology Today, 78-79.

Geher, G., \& Kaufman, S. B. (2011). Mating intelligence. In (R. Sternberg \& S. B. Kaufman, Eds.), The Cambridge Handbook of Intelligence. Cambridge. DOI

Geher, G., \& Kaufman, S. B. (2013). Mating intelligence unleashed: Why the human mind is sexy. New York, NY: Oxford University Press.

Geher, G., \& Miller, G. (2008). Mating Intelligence: Sex, relationships, and the mind's reproductive system. New York, NY: Taylor and Francis Group, LLC. DOI

Greitmeyer, T. (2005). Receptivity to sexual offers as a function of sex, socioeconomic status, physical attractiveness, and intimacy of the offer. Personal Relationships, 12, 373-386. DOI

Haselton, M. G., \& Buss, D. M. (2000). Error management theory: A new perspective on biases in cross-sex mind reading. Journal of Personality and Social Psychology, 78, 81-91. DOI

Hatfield, E., \& Sprecher, S. (1986). Mirror, Mirror...: The Importance of Looks in Everyday Life. Albany, NY: State University of New York Press.

Heatherton, T. F., \& Polivy, J. (1991). Development and validation of a scale for measuring state self-esteem. Journal of Personality and Social Psychology, 60, 895-910. DOI 
Hill, S. E., \& Buss, D. M. (2006). The evolution of self-esteem. In M. Kernis (Ed.), Self-esteem issues and answers: A source book of current perspectives (pp. 328-333). New York, NY: Psychology Press.

Hill, S. E., \& Durante, K. M. (2013). Do women feel worse to look their best? Testing the relationship between self-esteem and fertility status across the menstrual cycle. Personality and Social Psychology Bulletin, 35, 1592-1601. DOI

Janis, I. L., \& Field, P. B. (1959) Sex difference and factors related to persuability. In C. I. Hovland and I. L. Janis (Eds.), Personality and persuability (pp. 55-68). New Haven, CT: Yale University Press.

Jonason, P. K., Norman, P. L., \& Cason, M. J. (2009). The "booty call": A compromise between men's and women's ideal mating strategies. Journal of Sex Research, 46, 460-470. DOI

Neave, N., \& Shields, K. (2008). The effect of facial hair manipulation on female perception of attractiveness, masculinity, and dominance in male faces. Personality and Individual Differences, 45, 373-377. DOI

O’Brien, D. T., Geher, G., Gallup, A. C., Garcia, J. R., \& Kaufman, S. B. (2009). Self-perceived mating intelligence predicts sexual behavior in college students: Empirical validation of a theoretical construct. Imagination, Cognition, and Personality, 29, 341-362. DOI

Park, L. E., \& Maner, J. K. (2009). Does self-threat promote social connection? The role of selfesteem and contingencies of self-worth. Journal of Personality and Social Psychology, 96, 203217. DOI

Patrick, H., Neighbors, C., \& Knee, C. R. (2004). Appearance-related social comparisons: The role of contingent self-esteem and self-perceptions of attractiveness. Personality and Social Psychology Bulletin, 30, 501-514. DOI

Peterson, A., Carmen, R., \& Geher, G. (2013). Ovulatory shifts in mating intelligence. Journal of Social, Evolutionary, and Cultural Psychology, 7, 66-75. DOI

Peterson, A., Geher, G., \& Kaufman, S.B. (2011). Predicting preferences for sex acts: which traits matter most, and why? Evolutionary Psychology, 9, 371-389. DOI

Rand, C. S., \& Hall, J. A. (1983). Sex differences in the accuracy of self-perceived attractiveness. Social Psychology Quarterly, 46, 359-363. DOI

Tadinac, M., \& Hromatko, I. (2007). Own mate value and relative importance of a potential mate's qualities. Studia Psychologica, 49, 251-264.

Thornton, B., \& Moore, S. (1993). Physical attractiveness contrast effect: Implication for self-esteem and evaluations of the social self. Personality and Social Psychology Bulletin, 19, 474-479. DOI

Todd, P. M., Penke, L., Fasolo, B., \& Lenton, A. P. (2007). Different cognitive processes underlie human mate choices and mate preferences. Proceedings of the National Academy of Sciences of the United States of America, 104, 15011-15016. DOI

Wade, T. J. (2000). Evolutionary theory and self-perception: Sex differences in body esteem predictors of self-perceived physical and sexual attractiveness. International Journal of Psychology, 35, 36-45. DOI 
Wade, T.J., Auer, G., \& Roth, T.M. (2009). What is love: Further investigation of love acts. Special Issue: Proceedings of the 3rd Annual Meeting of the Northeastern Evolutionary Psychology Society. Journal of Social, Evolutionary and Cultural Psychology, 3, 290-304. DOI

Wade, T. J., Butrie, K. L., \& Hoffman, K. M. (2009). Women's direct opening lines are perceived as most effective. Personality and Individual Differences, 47, 145-149. DOI

Wade, T. J., \& Cooper, M. (1999). Sex differences in the links between attractiveness, self- esteem and the body. Personality and Individual Differences, 27, 1047-1056. DOI 